\title{
The Epistemology of the Question of Authenticity, in Place of Strategic Essentialism
}

\author{
EMILY S. LEE
}

The question of authenticity centers in the lives of women of color to invite and restrict their representative roles. For this reason, Gayatri Chakravorty Spivak and Uma Narayan advocate responding with strategic essentialism. This paper argues against such a strategy and proposes an epistemic understanding of the question of authenticity. The question stems from a kernel of truth-the connection between experience and knowledge. But a coherence theory of knowledge better captures the sociality and the holism of experience and knowledge.

Perhaps because women's bodies bear culture, women whose bodies visibly demonstrate a non-Western association-women with hyphenated identities-have questioned consistently their authenticity as Asians, Africans, Latinas, and so on. This could be considered an advance toward recognizing that citizens of the United States come from diverse backgrounds. But those with hyphenated identities are not readily accorded status as Americans. Women with hyphenated identities are left without any identity! Although as a concept, authenticity enjoys a privileged status in our society, the question of authenticity becomes ambiguous when directed at women of color. This paper examines the responses of two prominent women of color to the question of authenticity; I chose these two women because they both advocate strategic essentialism. Although I find their analyses compelling, the solution of strategic essentialism risks increasing epistemic confusion about the relation among embodiment, experience of a culture, and knowledge of a culture. This paper aims to clarify the epistemic relation among these three features because of their importance in the lives of third-world women. 
The paper is split into two parts. The first part explores the treatment of the question of authenticity by two prominent, third-world, feminist theorists, Uma Narayan and Gayatri Chakravorty Spivak. This first part consists of three sections. Section A explores the role of culture as the foundational basis of the question of authenticity. The question of authenticity arises because of a lack of correspondence between perceptions of third-world culture and the actions or behaviors of women of color. Section B notes a possible Foucauldian reason for posing the question of authenticity to women of color: to silence them. This attempt to silence confounds the participation of women of color in the important and intricate work of representing oneself and constructing the self. Section C addresses Narayan's and Spivak's responses to the question of authenticity. They advocate practicing strategic essentialism. I find this response unsatisfactory because the strategy does not increase understanding; rather, it promotes epistemological confusion.

In the second part, I explore the connection between the experience and the knowledge of a culture that lies at the heart of the question of authenticity for hyphenated identities. Perhaps the question of authenticity stems from a kernel of truth: the existence of a connection between experience and knowledge. To better understand this relation between experience and knowledge, I turn to coherence theories of knowledge. Coherence theories of knowledge accommodate both the social construction of experience and the social construction of knowledge. Coherence theories acknowledge the connection between experience and knowledge without direct experience and without experience as determinative of knowledge. Coherence theories of knowledge facilitate understanding that knowledge becomes knowledge only upon confirmation with others. In other words, aspiring to be an authentic self demands the process of negotiation, validation, and agreement with other human beings. This leaves the claims or attributions of women of color about proprietary experience of a culture in a tenuous position. Nevertheless, understanding knowledge as requiring social verification can call for discarding the authenticity question as directed to women of color.

\section{PART I}

A. Narayan and Spivak Respond to the Question of Authenticity: The Role of Culture as the Source for the Question of Authenticity

The question of authenticity posed to women of color centers around the role of culture. The question arises from a perceived epistemic incongruity, a lack of correspondence between an image - an idea of Asian culture, African culture, Latin culture, what have you-and the embodiment of women of color. ${ }^{1}$ The physical embodiment of women of color exhibits, beckons, provokes 
immediate ties with non-Western cultures, and yet the activities and expressions of these women, the active embodiments of these women, apparently do not correspond with understandings of the various cultures. The form of the question varies from actual incantations of the word "authenticity" to references to the "real" (as in real Asian) and "loyalty" (as in loyalty to one's culture as a source of identity or self-love). The question surfaces in a wide variety of circumstances ranging from casual social contexts to professional settings. The question of authenticity is posed by other hyphenated Americans, including those sharing the same hyphen, over eating preferences as well as from white philosophers over specializations.

The focus of the question of authenticity is unclear; it lacks specificity. At times it questions the authenticity of the subject herself, in its connotations that women of color are not authentic if their eating preference or behavior does not somehow reflect their culture. But at other times, it questions whether women of color know their culture. The slippage is understandable, following Charles Taylor and Linda Martín Alcoff's position that the self does not develop, does not come to self-understanding outside a relation with the other and a horizon of social meanings. Alcoff writes, "the Other is internal to the self's substantive content, a part of its own horizon, and thus a part of its own identity" (Alcoff 2006,82 ). If the self does not exist in isolation and is inherently social, the question of authenticity can slip ambiguously from questions of the self to questions about knowledge of a culture. Yet this slippage occurs especially about people of color, particularly women of color. I believe embodiment plays a central role for these encounters with the question of authenticity. Again, such slippage between the self and understanding of culture is not necessarily wrongheaded, but I want to draw attention to the role of embodiment that occasions, validates, and justifies the question. The embodiment of women of color suggests immediate ties between the self and the culture, concerning knowledge of the culture and concerning culture's impact on the self. Belief in such connections conditions the lives of women of color living in the West.

Most poignantly, this incongruity between the embodiment of women of color and the culture associated with such embodiment centers around feminist beliefs and inclinations. Too many people immediately read any signs of consciousness about gender-informed assumptions as a sign that the third-world woman has lost her authenticity. Members of both the first world and the third world view feminism as a product of the West (Narayan 1997, 3). ${ }^{2}$

This perceived lack of correspondence between feminist beliefs (apparently in all forms) and all third-world cultures arises from a mistaken notion of culture in general, as well as of third-world cultures. The mistake begins with an essentialist understanding of culture and spirals into essentialist ideas of third-world women, first-world women, and feminism. I hope that I am only reiterating commonly held knowledge in outlining the following three features 
of culture that claim determinative ties between experience and knowledge of a culture. First, culture is heterogeneous. The plethora of third-world countries, the various regions within a country, and one's individual circumstances within a culture-which include one's class, race, and gender-ensure a heterogeneous experience of one's culture. Second, all culture evolves and changes. Contrary to the common misperception of the static condition of third-world culture, third-world culture evolves just as dynamically as does first-world culture (Narayan 1997, 16; see also Mohanty 1984). Third, one must be suspicious of many of the prevailing images of third-world culture because they have arisen in intricate relation to the history of colonialism (Narayan 1997, 14). Narayan carefully explains that colonizers stressed the difference between the first world and the third world to justify colonizing; subsequently, the colonized also emphasized the differences between the first world and the third world to justify the colonized's work toward liberation from the colonizers. As products of colonialism, the initial images of third-world culture do not concern truth as much as they do the political efforts to emphasize the differences between the third and the first world.

In light of the postmodern conceptual framework that culture, and hence experiences of culture, are socially constructed - in this particular instance by the colonizers and the colonized-that culture is heterogeneous and changing should not surprise anyone. Under such circumstances, a lack of correspondence between third-world cultures and the active embodiment of women of color should occasion celebrating the challenges to the all-encompassing forces of social construction and not inspire the question of authenticity. Only if culture is homogeneous and if culture can be essentially known can it function as a model for judging the activities and beliefs of women of color. ${ }^{3}$ Only if culture statically persists and does not continually evolve can it provide a criterion for gauging the actions and behaviors of women of color. In understanding that colonialism has produced many of the prevailing images of third-world cultures, we should applaud incongruity in the embodiment of women of color as challenges to colonialism and not use the opportunity to raise the question of authenticity.

\section{B. The Attempt to Silence}

Considering the nebulous nature of culture, questions of authenticity, as persistent expressions of incongruity between the physical and the active embodiment of women of color, are curious. The suspicious mind might wonder if these questions of authenticity - far from being simple expressions of curiosity - may be presented to challenge the credibility of third-world women and their authority to speak.

Narayan writes that efforts to silence arise in situations of representing. She describes representing in three senses: first, as representing oneself; second, as 
representing others without their explicit permission — what Narayan calls an "empirical question"; and third, as representing others with their explicit authorization (Narayan 1997, 147). Narayan explains that invitations to represent assume third-world women can represent in all three senses. Yet such an assumption places the third-world representative into a structural, performative contradiction "where they have to resort to such disclaimers of 'representation' even as they carry out the function of being the sole 'representative' from a Third-World background" (144). Considering the heterogeneity of culture, Narayan posits that a single representative cannot provide a complete and accurate representation, especially in the second and the third senses. In addition to this structural contradiction, the question of authenticity poses a further challenge to women of color: the problem lies in the misperception of this knowledge as a specific kind, as non-scholarly. Narayan muses, "I am less amused when I wonder whether the part of my work that pertains to 'Third-World Issues' might seem like 'automatic knowledge' seeping from my Third-World pores, rather than the results of intellectual and political effort!" (145). Clearly Narayan's sarcasm voices her frustration with the presumption that her knowledge of third-world culture somehow naturally occurs. As non-scholarly, the criteria for evaluating disagreements in this area of knowledge focus "in terms of the 'relative authenticity' of the two individuals, rather than in terms of critical substance" (151). Under such circumstances, the question of authenticity interjects and discredits the representative if the representative does not represent in the second and third senses of representation as expected — ways that correspond with images of third-world culture. ${ }^{4}$ In these moments of disappointment or defiance, the question of authenticity enters to challenge the rights of women of color to speak: to silence women of color.

Let me interrupt this straight reading of Narayan's book by introducing an earlier work by Alcoff. Her article, "The Problem of Speaking for Others," complicates Narayan's demarcation of the three senses of representation. First, Alcoff challenges the possibility of distinctly separating the three forms of representation. In the event of representation, she explains the difficulties of distinguishing the process of speaking for and speaking about and the process of representing solely me and representing others (Alcoff 1991-92, 9-10). Alcoff writes, "[i]n both the practice of speaking for as well as the practice of speaking about others, I am engaging in the act of representing the other's needs, goals, situation, and in fact, who they are, based on my own situated interpretation. In post-structuralist terms, I am participating in the construction of their subjectpositions rather than simply discovering their true selves" (9).

I especially appreciate Alcoff's point because she emphasizes the importance of acts of representation. Let me clarify, however, that whereas the two philosophers speak only about formal occasions of representing, I suggest that particularly with regard to the embodiment of women of color, they are always 
in some sense representing, especially in any public setting. Endemic to the embodiment of women of color are perceptions that they always represent their culture and others resembling their bodies. Consistent with the overdetermination of people of color who are always held responsible "for my body, my race, my ancestors" (Fanon 1967, 112), because of women of color's embodiment they cannot but be taken as representative in the three senses that Narayan, outlines even in the most casual, ordinary settings. Lived experience is representative existence for people of color. Because the bodies of women of color are taken as representative in the three senses, the question of authenticity slips so easily between questions about the selves of women of color and the knowledge of the presumed culture associated with women of color.

During the event of representation, whether the event is official or inevitable, one engages in the process of constructing subject-positions-of oneself and of others. If we recognize the heterogeneity, evolution, and social construction of culture, the subject as third-world woman must also be socially produced. Images of women of color in their overdetermination are precisely produced. Under such circumstances, only by engaging in the process of representation can third-world women like Narayan participate in this important work of the subject-formation of third-world women, of defining third-world women. ${ }^{5}$ Hence when the question of authenticity interrupts her endeavors at representation, the question attempts to silence and prohibit her from engaging in the process of subject-formation.

\section{Strategic Essentialism}

Narayan and Spivak advise strategically occupying the status of authenticity: they recommend practicing strategic essentialism (Grosz 1985, 184; Narayan 1997, 154). ${ }^{6}$ Spivak advances strategic essentialism not simply as a strategy for moments of representing, but conceptually to theoretically address essentialist ideas. Working within a post-structuralist framework, Spivak argues that the structure of language prohibits anti-essentialist ideas from existing outside of a dichotomous relationship to the essentialist ideas-one is or is not essentialist. The position of anti-essentialism requires engaging, relating, and ultimately validating essentialism. ${ }^{7}$ Spivak's analysis specifically concerns feminism and the question of how to accommodate the demands of third-wave feminism, but her analysis applies to general essentialist ideas. Spivak explains:

I am fundamentally concerned with ... heterogeneity but ... I felt that rather than define myself as repudiating universality, because universalization, finalization, is an irreducible moment in any discourse-rather than define myself as specific rather than universal-I should see what in the universalizing dis- 
course could be useful. ... I think we have to choose again strategically, not universal discourse but essentialist discourse. $($ Grosz 1985, 185)

In conceptualizing "feminism," and even in defining "woman," both terms are already linguistically mired in essentialist ideas. As a result, any attempt to theorize "woman" demands beginning with denials of the essentialist ideas depicted in the word "woman" (Grosz 1985, 185). ${ }^{9}$ Yet positing specificity denies all possibility of theoretical engagement to the extent that theory requires some universal insight. Hence, to reach out of the entangling conceptual structure of essentializing ideas and language, but without giving up all hope of participating in theory making, Spivak advocates a strategy. A strategy is not a theoryits method is not universal - but with each encounter, a strategy plays with the essentialist ideas in a wily way and continues to participate in theory-making, if only by disrupting the process. With such play and mimicry, a strategy can subtly demonstrate the limits of essentialist ideas, even as the strategy acknowledges the inability to avoid essentialism.

Facing persistent criticisms concerning strategic essentialism, Spivak eventually moves away from this position. In an interview with Ellen Rooney, Spivak explains, "[w]hen I began to write as a feminist, the idea of differences being unjustly made and unjustly not recognized needed the presupposition that what was self-same or identical was an essence. It was okay as a strategic presupposition. ... But it does seem that like most strategies ... it has served its purpose, and at this point I can't go on beating that horse anymore" (Spivak 1989, 144).

Nine years after Spivak ceased advocating strategic essentialism, Narayan nevertheless forwards it specifically in moments of representing. She recommends to "Third-world feminists confronted by these roles ... a strategy of both acceding to these roles and exceeding them. One might find it useful to "strategically occupy" these roles while also calling attention to one's strategy of occupation. One may find it useful to occupy these roles even as one mocks them, laughs at some of their absurdities, and complains about their limitations" (Narayan 1997, 155). In the face of the persistent belief in a colonialistic, homogeneous, and static picture of third-world culture, Narayan recommends acceding to essentialism at times for the opportunity to represent and to disrupt the prevailing images of third-world subjects.

Narayan advocates this strategy even while recognizing it as dangerous. Two dangers permeate the strategy of essentialism. First, practicing strategic essentialism maintains perceptions that knowledge of third-world culture is non-scholarly, with its attendant status as beyond the purview of criticism and analysis. As previously mentioned, this position exposes the speaker's knowledge to evaluations on the basis of relative authenticity. Second, this strategy makes the speaker vulnerable to the judgment that she can speak only 
on that particular subject (Narayan 1997, 144). Narayan writes, "[t]he assigned 'proprietary' relationship between the 'Authentic Insider' and 'her culture' can therefore function as a threshold of 'proprietary,' whereby the 'Insider's' desires to talk about contexts other than her 'own' acquire the mark of impropriety" (144). Strategic essentialism serves as ingress to claims of proprietary knowledge for opportunities to represent, but it also invites questions of authenticity that prohibit participation in other domains of knowledge. The strategy thus functions as a double-edged sword.

I have an additional misgiving about this strategy. In cultivating the perception of an authentic representative of third-world culture, strategic essentialism keeps alive the image of a homogeneous, static, and essential third-world culture. Moreover, it facilitates the idea of a determinative relation among embodiment, experience of a culture, and knowledge of the culture. Strategic essentialism ultimately supports epistemological confusions that permit, indeed incite, questions of authenticity. I question the ultimate benefit of forwarding further epistemic confusions about third-world culture and the relation among embodiment, experience, and knowledge of a culture. ${ }^{10}$ The practice of strategic essentialism may suffice in the immediate future to mimic essentialist ideas to the benefit of particular individuals, but it does not ultimately help to clarify misconceptions about third-world culture, third-world women, and feminism.

\section{PART II}

\section{The Epistemic Basis of the Question of Authenticity: The Relationship Between EXPERIENCE AND KNOWLEDGE}

Understandably, women of color view the question of authenticity with suspicion. There is something deeply unsatisfying about where the above discussion ends. A strategy just does not address the depth of the questions of what is the self, how does the self develop, and how does one know oneself and one's world-concerns inherent in the question of authenticity. More importantly, pondering the authenticity of hyphenated identities — with all its intricacies and complications-should contribute to the philosophical endeavor of the question of authenticity. In the difficult work of authentically being/living, identities marked by difference, duality, and inherent complexity should bring insight to this area of philosophy. Hence, acknowledging Narayan and Spivak, I start anew with the belief that the question of authenticity holds a kernel of truth.

I focus on the epistemic relation among embodiment, experience of a culture, and knowledge of a culture, specifically the assumption (conscious or not) of a determinative relation among the three. Epistemologically, the question of 
authenticity arises because of a belief in some sort of a connection between one's experience and one's knowledge. The physical features of women of color suggest they have lived and developed within a particular culture at least for some period of their lives, and have experienced such a culture- these physical features subsequently imply they know the culture. Recognizing this prevailing belief in the connection between experience and knowledge, Narayan withholds from relinquishing her status as an authentic insider to third-world culture. Narayan insists, "[t]o surrender the possibility of any connections between who I am and what I know is ... to surrender my standing to speak as an 'insider' to Third-World contexts, a standing that many Third-World feminists are often denied simply by virtue of their feminism. This is a denial whose legitimacy is precisely what I wish to question" (Narayan 1997, 5). Nevertheless, she avoids making too immediate a connection between experience and knowledge, by specifying the connection between her knowledge and experience as linkages and not determinates. Narayan writes, "I do not 'locate myself' or specify who I am because I 'assume ... who I am determines what and how I know'... I do, however, wish to suggest some linkages between the complexities of who I am and what I claim to know. By 'linkages,' I wish to suggest weaker forms of influence or connection than is suggested by the term 'determined"' (5). In claiming these linkages, Narayan admits a connection between experience and knowledge of culture. She recognizes that while heterogeneous and changing, culture is still knowable.

A large body of work explores this connection between experience and knowledge. ${ }^{11}$ Interestingly, the postmodern turn threw into doubt the direction of this connection, whether experience contributes to knowledge or knowledge makes sense of experience. If the postmodernists persuasively demonstrate the social construction of experience-a position that I more or less admit in my earlier discussion of the importance of engaging in representation-then experience cannot provide knowledge. Rather, some argue, knowledge necessarily organizes the meaning of experience. I am persuaded by work that posits more of an inherent cognitive component in experience, if anything, that concepts and thoughts immediately and already mediate experience (Mohanty 1997, 205). Regardless of which direction one finds persuasive, the question of authenticity appears-to the extent that it questions whether one experiences a culture-epistemologically valid. If experience has cognitive value, if experience relates to knowledge whether immediate or not, questioning whether one truly experiences a culture is sound.

\section{THe Structure of Justification}

To better understand this connection between experience and knowledge as it functions in the question of authenticity, I turn to a coherentist theory of the 
justification of knowledge. ${ }^{12}$ Coherence theories of knowledge-more than foundationalist or correspondence theories of knowledge-accommodate the social constructedness of culture and experience of culture. Coherence theories of knowledge acknowledge the heterogeneous, changing, and constructed state of both the subject matter (culture and the experience of culture) and the means/tools through which to know culture. Correspondence theories of knowledge are not directly helpful here because they understand knowledge as actually somehow matching up with the world and hence do not accommodate experiencing and knowing culture as socially constructed.

Let me clarify that this paper does not defend coherentism as a whole. I simply utilize it because it most consistently depicts the scenario that I address within this paper: the social construction of both experience and knowledge. Therefore, the following does not comprise a wholehearted endeavor to defend coherentism. The present concern of the question of authenticity limits the extent of my defense of coherentism.

To illustrate why coherentism accommodates the structure of experience as it relates to knowledge in the question of authenticity, I turn to the work of W. V. O. Quine with the help of Lynn Hankinson Nelson and other coherentists. ${ }^{13}$ Let us begin with Quine's denial that experience, including sensory experience, serves as the extra-theoretical evidence to found scientific knowledge. ${ }^{14}$ Quine insists that one cannot distinguish observation sentences from theoretical sentences in either degree or kind; pure sensory experience does not exist (Quine 1953, 42). The problem lies in determining the empirical content of the observation sentences. One cannot isolate the empirical content of observation sentences from the existing body of knowledge and theories because theories determine the empirical content. One cannot form or utilize observation sentences separately from the existing body of knowledge. ${ }^{15}$ Hence coherence theory avoids the postmodern critique that experience is socially constructed and cannot contribute to knowledge. Coherence theories commence with understanding the integral relation between experience and knowledge.

Let me clarify two consequences of this integral relation between experience and knowledge. Coherentism is not foundationalist. With a holistic view of knowledge, all knowledge evolves. Foundationalism upholds two claims. Alcoff explains these two claims: "1. that there are basic beliefs of some sort, beliefs that are not justified by other beliefs; and 2. that the structure of knowledge is such that these basic beliefs serve as the foundation of all others" (Alcoff 1998, 295). Coherentism does not uphold these two claims. All aspects of knowledge within this framework are subject to change and to justification; coherentism rejects foundationalism.

Second, without relying upon observation sentences about one's experience of the world, and without a foundationalist framework of knowledge, coheren- 
tism utilizes non-linear justifications of knowledge. It contrasts with "the idea that inferential justification is essentially linear in character, that it involves a one-dimensional sequence of beliefs, ordered by the relation of epistemic priority, along which epistemic justification is passed from the earlier to the later beliefs in the sequence via connections of inference" (Bonjour 1985, 90). In other words, linear forms of justification utilize a unidirectional justification, insisting that only initially justified premises can subsequently confer justification on the consequence. Laurence Bonjour explains that relying exclusively upon linear justification may be appropriate for local forms of justification, but for global justification, linear justification does not suffice. Relying purely on linear justification neglects the possibility of justifying the overall system of empirical beliefs (90-92).

The non-foundationalist, non-linear justification of coherence theories of knowledge structurally depicts the experience and knowledge of culture. Because culture changes, no experience of a culture is foundational; and because history and politics struggle to define and to represent culture, knowledge of culture develops non-linearly. Non-linear justification, especially, accurately describes the struggle among members within a culture to define themselves and members outside of a particular culture in their attempts to exoticize, colonize, communicate, and understand difference.

Without foundationalism and linear forms of justification, coherentism advances that theories address the world as a whole. Satya Mohanty explains that within a coherence theory of knowledge, "we justify knowledge ... not by holding up isolated claims to see how they 'fit' with 'the world' but rather by examining their coherence with everything else we know" (Mohanty 1997, 150). Here lies the central difference between coherence theory, in its various instantiations, and correspondence theory. Recall that Quine denies the possibility of observation sentences that merely reflect and represent the world. Knowledge is holistic; "confirmation involves the background theories and auxiliary hypotheses" (Mohanty 1997, 187). Coherence theory insists on holistic criteria for knowledge.

This denial of observation sentences that found knowledge claims does not necessitate the denial of the influence of the material, empirical world on knowledge. Quine is an empiricist; he accepts that the world constrains our knowledge. But Quine argues that the world and our prevailing, already existing body of theories together further constrain our knowledge claims. ${ }^{16}$

With this non-foundationalist and holistic means of knowing, Nelson explains that "Quine maintains that there is no possibility of a 'wholesale' rejection of the network" (Nelson 1990, 89). Rather, adjustments in the interior of the network accommodate the experiences that call for changes in knowledge. Without a wholesale change of the network, the network absorbs any changes in knowledge that the varied experiences of a culture demand. 
Quine writes, "[a] conflict with experience at the periphery occasions readjustments in the interior of the field. Truth values have to be redistributed over some of our statements. ... But the total field is so underdetermined by its boundary conditions, experience, that there is much latitude of choice as to what statements to re-evaluate" (Quine 1953, 42-43). ${ }^{17}$ These words point to the malleability of the theoretical network. Consequently, there is slack between evidence/sensory experience and the network of knowledge; evidence that absolutely determines a specific theory does not exist. Rather, one set of evidence can support more than one theory. ${ }^{18}$ The network of knowledge is fluid; no part of the network remains immune to the possibility of revision.

Without an essential experience of culture, the holism of coherence theory depicts not only the structure of knowledge but the structure of experience. For how does one know when one is experiencing culture? When does the experience of culture begin and end? Does eating Indian food in Orange County constitute an experience of Indian culture? Is one beginning the experience when one enters the restaurant or when one begins to eat the food? Does knowing that many Indian restaurants are actually run by Sri Lankans change the experience? Because the experience of culture is not defined by length of time or exposure to any one feature, the structural experience of culture is necessarily holistic. Moreover, there is much slack between experience and knowledge of a culture.

Coherence theory leads to the conclusion that " $[\mathrm{k}]$ nowledge ... is social in every sense, it is constructed by us, and it is constrained by our experiences" (Nelson 1990, 40). Contrary to the position of correspondence theories of knowledge, we neither discover theories nor objects. This is one of the most important features of coherentism; it recognizes not only the social constructedness of experience, but the social constructedness of knowledge. ${ }^{19,20}$ Poststructuralist theories had already argued the social construction of experience. Here, let me emphasize how coherence theory concludes that knowledge is socially constructed. ${ }^{21}$ This conclusion within coherence theory nicely captures the structure of cultural knowledge, for after all, culture is obviously socially constructed. Coherence theory, with its non-foundationalist, non-linear, holistic justification that acknowledges the non-determinativeness between experience and knowledge, helps to epistemically understand the holistic structure of experience and the social construction of knowledge of culture.

Nelson explains an important implication of understanding the social construction of knowledge. She asserts that with a coherentist theory of knowledge, human beings do not come to know individually and then contribute to the body of knowledge, but that we only initially come to know as a community, as a group. Quine, along with all empiricists, mistakenly assumes that individuals, as individuals, come to know. Empiricists believe that individuals know in a primary rather than a derivative sense. The individually held 
knowledge develops into the knowledge of communities. Contrary to Quine, but perhaps more consistent with his holism, Nelson argues that empiricism actually encompasses a communalist position. She clarifies that when we know, the we cannot form from the addition of one individual plus another individual, ad infinitum. Rather, we know because we, as a group, possess knowledge; each individual comes to know derivatively as a member of the group.

Nelson gives two reasons for this conclusion. First, she intuitively argues that our confidence in generalizing from our situation to others originates from the belief that we are we as a group first and not as a result of the additions of one plus one (Nelson 1990, 285). ${ }^{22}$ Second, recall Quine's stance that we cannot derive the empirical content of statements outside of our going network of theories- that extra-theoretical pieces of evidence do not exist. Such a position necessitates that a public standard determines evidence (277). Analogously, if extra-theoretical statements do not exist, neither do extratheoretical experiences. Hence, individuals cannot know in isolation. We must know as a member of a group first and foremost. Nelson writes, "[m]y claims to know are subject to community criteria, public notions of what constitutes evidence, so that, in an important sense, I can know only what we know, for some we" (255). ${ }^{23}$ Nelson persuasively argues that with a coherentist conception of knowledge, knowledge claims to know cannot arise initially individually. Even if one discovers or builds something new, to be accepted as knowledge it must undergo community confirmation and justification; our ongoing body of knowledge must entail the new experience/knowledge. ${ }^{24}$

\section{The Implications of KNowledge as Socially Constructed And COMMUNITY-AFFirmed FOR THIRD-WORLD WOMEN}

Returning to our original problem on the question of authenticity, my long divergence into coherence theory serves to illustrate a theory of knowledge, of epistemic justification, that challenges the correspondence basis that validates the question of authenticity. The acceptability of the question of authenticity comes from the presumed correspondence between third-world women's immediate experiences of a culture that grounds proprietary claims to knowledge of the culture. Coherence theories of knowledge accommodate the heterogeneity, the change, and the construction of all three features: experience, knowledge, and culture. Coherence theories of knowledge also accept the open-ended, holistic particularity of experience. Hence, although the question of authenticity begins with correctly assuming a connection between experience and knowledge, the question does not recognize that this relation is not determinate, yet much more immediate and complex, because cognition imbues experience while sociality and community constrain knowledge. Knowledge of a culture does not develop solely from visceral experience but 
must fit with the ongoing web of knowledge and be confirmed by the community. In other words, one can learn about a culture, and individual visceral experience of culture does not found experience.

With a coherence conception of knowledge, and the subsequent conclusion that "we" know as some "we," what exactly constitutes experience and knowledge of culture? For first second generations in the United States, many students of color learn about their parents' countries of origin, including their culture, history, and language in college classrooms or subsidiary education. These students' embodiment suggests the likelihood of experiencing a certain culture but, without the experience of their parents' culture associated with authenticity in its correspondence sense, with only indirect experience of their parents' culture, they may nevertheless know quite a bit about their culture.

Alternatively, their parents, the immigrants, have the experience of their original culture that is usually associated with authenticity in its correspondence sense. But they may have an understanding of their culture that originates from a frozen time period, frozen at when they left their countries of origin. ${ }^{25}$ Thus, these immigrants may have only a historical and limited understanding of their first culture.

Finally, depending on one's position in a society, one may mature entirely within a culture and not possess a breadth of understanding about one's culture. Sandra Harding's work explains this possibility in regard to gender through the idea of situated knowledge. Harding and others argue that gender forms an experiential divide in a society so formative that it influences if not quite determines what each gender knows about the society they share (1991, 120). Harding follows Marx's analysis regarding the epistemic divides, especially between the bourgeoisie and the proletariats, because of class lines. To a certain extent, such lack of understanding of the entire culture occurs within any class, but it is particularly evident among people from the lowest and the highest classes. Life within the poorest class in any society entails a lack of education, which leaves one bereft of knowledge about particular aspects of one's culture. Similarly, the isolation within the excessive, materialistic comforts among the extremely wealthy tints and biases their knowledge about their culture. As Edward Sherman writes, "[i]t would not be enough to have an everyday, uncritical understanding of our tradition because we may misrepresent, misunderstand, or be incapable of articulating those goods that serve as the background of our social world" $(2005,153)$.

Let me clarify that this does not entail that all people who undergo a specific experience all arrive at the same beliefs about the world ${ }^{26}$ If experience is determinative, then the question of authenticity is wholly acceptable! Yet, all women do not understand gender the same way, nor do all the poor comprehend their culture similarly. Rather, the coherentist framework better explains the possibility of how, although one undergoes similar experiences as others, 
one may still come to different conclusions. One understands one's present experiences through the culmination of one's knowledge and previous experience and the communities within which one participates. As such, the extent to which women of color know about their cultures of origin is not because they all undergo the same immediate/visceral/ineluctable/mysterious/individual contact with their cultures and draw the same conclusions. Their previous negotiations, communications, confirmations, and justifications with other members of the culture form the lens for understanding their experiences.

Between the first second generations and the individuals with "authentic" experience, it is arguable which group might possess more knowledge, qualitatively and quantitatively, of the culture. I realize that this position opens up the possibility of expatriates, specifically those from the first world, who lived for a couple of years in the third world and claim knowledge about it. Edward Said disparages precisely such claims to knowledge by expatriates as "experts" on the third world in his now famous text, Orientalism. Actually, some claims of expert status did not even require a visit to the Orient. Yet, I leave open this possibility with its attendant dangers of orientalizing, exoticizing, projecting psychosis, and simply misunderstanding the third world. I accept this possibility because it is the logical consequence of comprehending knowledge of culture in a coherence sense, through a combination of experiencing, learning, and confirmation by members of our community - and not only through direct experience in the correspondence sense. Moreover, consistent with the changing nature of culture, I want to remain open to continual endeavors to gain knowledge. I do advise caution regarding claims to knowledge about thirdworld culture by expatriates because of the role embodiment plays in experience. For because of one's embodiment, no matter how long one lives in a foreign country, one may never experience the same experiences as individuals whose embodiment reflects the region or country. Keep in mind that these do not comprise isolated experiences but an accumulation of experiences. Because of the specific experiences available to particular forms of embodiment, expatriates need to exercise care in their knowledge claims about thirdworld culture.

\section{CONCLUSION}

The question of authenticity originates in truth because a relationship exists between experience and knowledge. Consequently, questioning the cultural experience of women of color truly is valid. Nevertheless, the question of authenticity reveals a naiveté about the structure of experiences, the structure of knowledge, and the structure of culture. Experience of a culture is both subtle and complex because experience is socially constructed and holistic. No one particular experience founds knowledge claims. Interestingly, coherence 
theories of knowledge explain that knowledge is also socially constructed, thus, fortunately, knowledge of culture is communicable, shareable, and hence learnable.

Questioning women of color about their authenticity clearly stems from an epistemological confusion that a certain experience of culture founds knowledge of culture. The persistence of this belief in a correspondence relation between experience and knowledge of culture leads Narayan to suspect that the question works to silence third-world women. Rising to this challenge, she rejuvenates an early strategy from Spivak and advocates that third-world women practice strategic essentialism and not renounce opportunities to represent. Rather than simply proffering an epistemically confused strategy, let us recognize that the question of authenticity reveals a lack of understanding about the coherence relation between experience and knowledge of culture. With a coherence theory of knowledge, and understanding that knowledge of thirdworld culture does not proprietarily rely upon visceral experience, I hope people will cease to raise the question to challenge the knowledge claims of women of color when they are representing. I do not want to hastily call for the rejection of the concept of authenticity, especially because it is such an important concept in the phenomenological/existential tradition. ${ }^{27}$ Nevertheless, challenges to representation and knowledge claims should be based not on a mistaken belief in visceral experiential claims of the subject herself, but on the defensibility, the logic, and the holism of her knowledge claims. If moments of representation present the opportunity for participation in the process of creating oneself and one's culture, then surely women of color must participate in these processes.

\section{NOTES}

I want to thank Marjorie Jolles for her comments on an earlier draft of this paper.

1. A comparison between the notion of authenticity in relation to race and to third-world culture would be interesting but would take me too far afield; see Monahan 2005, 39 for a comparison in regard to race. He writes, "[t]he dominant essentialist approach assumes a kind of correspondence theory of authenticity - to be racially authentic is to behave in a manner that corresponds to one's racial reality."

2. Uma Narayan writes that in an unusual union, members of the third world and the first world question her as "lacking the 'real authenticity' of a 'true native"' (Narayan 1997, 145). See also Williams 1991, 10. A variety of people question whether she identifies as black.

3. Michael Walzer expresses a similar critique of Jean-Paul Sartre's Anti-Semite and Jew. Walzer argues that Sartre holds an essentialist view of Jewish culture (Walzer 1995, xxiii).

4. Narayan further points out that the question of authenticity is imposed upon "the 'discovery' of the Insider's inability or refusal to 'be representative' in the second 
and third senses of the term, works to devalue and invalidate her 'representations' or accounts in the first sense" (Narayan 1997, 147). Hence, the question ultimately challenges even her ability to represent herself as well.

5. I am not sure that Narayan's work can accommodate this post-structuralist language. Nevertheless, this is where I would like to go.

6. I cite Grosz because Grosz published an interview with Spivak that contains one of the first instances, if not the first instance, of Spivak articulating the notion of strategic essentialism. I cite only Spivak's words.

7. Referring to a specific instantiation of this inevitability, Spivak says, "[i]f you just define yourself as anti-sexist you are indeed legitimizing sexism" (Grosz 1985, 184).

8. Specifically in regard to the difficulties of de-essentializing the notion of woman, in a separate article Spivak writes, "a figure of 'woman' is at issue, one whose minimal predication as indeterminate is already available to the phallocentric tradition. . . For the 'figure' of woman, the relationship between woman and silence can be plotted by women themselves; race and class differences are subsumed under that charge" (Spivak 1988, 287).

9. The specific quote reads, "how can the unexamined universalizing discourse of a certain sort of feminism become useful for us since this is the hegemonic space of feminist discourse ... in working out the heterogeneous production of sexed subjects."

10. Alcoff also expresses misgivings about strategic essentialism. She argues that the solution of strategic essentialism demonstrates "an inherent elitism and even vanguardism in the split between the 'knowing' theorists who deploy identity strategically and the 'unknowing' activists who continue to believe in essentialism" (Alcoff 2000b, 323). Satya Mohanty also expresses dissatisfaction with this strategy. He writes, "such weak theoretical compromises as are suggested by such terms as 'strategic essentialism' are based on an evasion of the difficult but unavoidable epistemological questions" (Mohanty 1997, 232).

11. See Scott, 1991; Dingwaney and Needham 1996; Moya 1997; Alcoff, 2000a; Stone-Mediatore 2000.

12. I address all forms of knowledge: propositional, emotional, and ineluctable. I realize that because of the specific kind of experience I address here, I may be misread as addressing only experiential knowledge. But I do not find this helpful, especially because I question such clear demarcations of knowledge.

13. Laurence Bonjour expresses suspicion of whether Quine really adheres to a coherence theory of knowledge. Bonjour writes, "Quine ... seems plausible that his position is some sort of coherentism (or perhaps weak foundationalism-I find it impossible to tell)" (Bonjour 1985, 249; see footnote 1 from Appendix B). Moreover, based on Quine's work on translations, Jonathan Dancy also suspects that Quine does not consistently rely on coherentism (Dancy 1985, 97-108). Quine's work after 1990, especially after The Pursuit of Truth, appears further afield from coherentism. Here he seems closer to foundationalism, particularly in his understanding of observation sentences. (I thank one of the blind reviewers of this article for directing me to this detail in Quine's work.) Nevertheless, I read him more generously and include him as a coherentist. 
14. Quine refers specifically to scientific knowledge, but I elide the distinction here because I contend there is a slippage between scientific knowledge and knowledge in general in Quine's work.

15. Quine rejects dividing truth into analytic and synthetic truths (Quine 1953, 37). Mohanty explains, "Quine points to the inevitable need for 'theory' in the most basic confirmatory practices of science, since even 'observation' is profoundly mediated by conscious or unacknowledged presuppositions about the world" (Mohanty 1997, 152). Lynn Hankinson Nelson similarly writes, "Quine denies the dualism of 'organizing scheme' and 'that to be organized"' (Nelson 1990, 26).

I understand that one of the biggest difficulties with the coherence theory of knowledge circles around its account of truth. This being so, even among self-professed coherentists, many still adhere to a correspondence theory of truth, even as they vehemently advocate coherentism for a theory of justification. I withhold from entering this important discussion within this paper. I only offer a quote from Alcoff on the coherentist account of truth. She claims that her account "is held by such philosophers as Rorty, Donald Davidson, Quine, and (I would argue) Gadamer and Foucault, truth is defined as an emergent property of converging discursive and non-discursive elements, when there exists a specific form of integration among these elements in a particular event" (Alcoff 1991-92, 14).

16. So what does coherence or holism mean? What does it mean to determine knowledge claims without distinguishing between observation and theoretical sentences and without linear forms of justification? With what criteria can we judge an increase or decrease in coherence to accept claims as knowledge? A considerable amount of work attempts to clarify this. Bonjour suggests the criterion of "inference," as "any sort of relations of content which would allow one belief or set of beliefs, if justified, to serve as the premise(s) of a cogent epistemic justificatory argument for a further belief" (Bonjour $1985,96)$. Bonjour's criterion of inference is perhaps the most inclusive and general. Inference requires only a belief or set of beliefs to infer another belief in order to increase the coherence of the network by being truth-preserving. Inference does not require a direct relation from the belief to the network, but only among the beliefs. Attempting to be more specific, Brand Blanshard advocates "entailment" to determine increases in coherence, "'in which every judgment entailed, and was entailed by, the rest of the system”" (96). Blanshard's entailment more constrictively requires coherence in both directions between a belief and the system for increases in coherence. Entailment requires both that individual judgments increase the coherence of the system, and that the system increases the coherence of the judgments at once. Concerned that Blanshard's entailment may be too constrictive, A. C. Ewing drops one of the directions of entailment, that individual judgments support the system. He relies solely on the system entailing the judgment to determine if the judgment adds to increasing the coherence of the system (97).

Bonjour explains that Ewing's dropping of this criterion subjects the system to becoming increasingly insular. If entailment directs only from the system to determine the acceptability of the beliefs, there is no way to test the coherence of the system as a whole.

17. Positions like these persuade me to think that Quine's network encompasses all forms of knowledge. 
18. Nelson clarifies that the slack exists in two ways: 1 . between theories and our evidence for them; and 2. between the questions we pursue and our going theories (Nelson 1990, 174).

19. Let me address three standard objections to coherentism. With regard to the most important, coherentism's relation to truth, I already admitted earlier that I cannot delve into this question here, nor do I think this necessary for the present project. Critics of coherentism present two remaining important objections: 1 . coherentism cannot justify a unique network of knowledge; and 2. coherentism maintains as a puzzle whether the system actually matches up with the world. Addressing the first, Bonjour elaborates that coherentism entails more than just consistency; the possibility of a plethora of other competing networks remains limited (Bonjour 1985, 107). But more importantly, he posits that on any standard account of epistemic justification, competing empirical claims are possible; the lack of a unique network of knowledge is not unique to coherentism and hence not devastating. Additionally, Bonjour insists that in the long run, alternative knowledge systems will disappear (144).

In response to the second objection regarding coherentism's inability to decide whether the knowledge system actually matches up with the world, Bonjour gives the standard response that beliefs are "caused in regular ways by the world" (140). Bonjour understands observation sentences differently, "as a regulative metaprinciple, as opposed to a first-level epistemic principle" (143). I want to clarify that this objection to coherentism fails to recognize structurally the fundamental insight of coherence theorythe impossibility of extra-theoretical observation sentences. In other words, there are no observations, no experiences, and no sensory experiences separate from theory to serve as foundations and confirm that the ongoing knowledge field actually reflects the world. This being so, Jonathan Dancy insists that all experiences possess cognitive elements: "it is impossible to draw a suitable distinction between the cognitive and the sensory 'elements' in sensory experience. ... If a coherentist requires for justification that all cognitive elements be interconnected, there is no possibility that beliefs wholly disconnected from sensory experience might yet count as justified, once we take experience to be cognitive" (Dancy 1985, 120-21). A central tenet of coherentism premises the impossibility of delineating aspects of the world and our ongoing theories. Again, both experience and knowledge are socially constructed.

20. Nelson explains that Sandra Harding strongly criticizes empiricism and particularly Quine's holism. Concentrating only on Harding's criticisms of empiricism applicable to Quine, she finds problematic four positions in his theory. I note only two in this footnote because of their greater relevance to the project at hand. I do not include them in the body of this paper because these criticisms apply to most epistemological theories. As Nelson explains, first, Quine maintains objectivity through the exclusion of values (Nelson 1990, 260). As an empiricist, he holds that the world constrains our experiences, and the web of knowledge ensures objectivity. He holds values to be beyond such empirical controls (131). Quine has a rather simplistic view that all values arise from natural selection and hence more or less similarly reflect most people and societies (132). Harding does not see the necessity of excluding values to achieve objectivity. Rather, Harding's epistemological standpoint arises through the political activism of feminists; politics and values provide essential sources of epistemological 
advantage. Nelson continues that, second, Quine maintains that anyone can verify "objectively produced claims." He gives two reasons for this belief: 1 . the larger social community does not influence scientific theories; 2 . common sense is "trans-historical and virtually exhausted by 'physical-object theory"' (Nelson 1990, 183). Quine holds that physical-object theory encompasses all common sense; theories about our material relations with the world exhaust our common sense. As such, physical object theory will eventually accommodate any differences in sex/gender within our common-sense understanding. This implies that Quine believes that common sense about streets and buildings accounts for women learning to avoid dangerous social situations (dangers specific to the female gender). Obviously, Quine has a rather naïve understanding of common sense. Nelson points out that this discussion of common-sense theory implies that he does not recognize the possibility that "experiences within our larger social community might be fundamentally and extensively divided" (Nelson 1990, 260).

21. I am not sure coherentist theorists would appreciate this language, but the language is helpful for consistency.

22. I do not find this intuitive position persuasive; but nevertheless, let us continue.

23. Nelson concludes that Quine should not rely on a naturalistic common sense to know individually; rather, he should rely upon the knowledge of communities (Nelson 1990, 285).

24. Dancy explains that Nicholas Rescher concludes this as well. Dancy writes that coherentism "directs attention away from the individual's struggle to construct his own epistemology, which is the classical conception of the epistemological enterprise; instead it gives a sense to the notion of knowledge as a social phenomenon, something that can be shared and which can increase by means of that sharing" (Dancy 1985, 119). Alcoff also elaborates on this position: "we cannot neatly separate off our mediating praxis which interprets and constructs our experiences from the praxis of others. We are collectively caught in an intricate, delicate web in which each action I take, discursive or otherwise, pulls on, breaks off, or maintains the tension in many strands of the web in which others find themselves moving also. When I speak for myself, I am constructing a possible self, a way to be in the world, and am offering that, whether I intend to or not, to others, as one possible way to be" (Alcoff 1991-92, 10).

25. Humorously, my parents, who immigrated to the United States, came to this conclusion about their understanding of Korean culture. On the occasion of meeting their future daughter-in-law, they worried that she may be too "free-spirited" because she is from Korea. Korea has changed so much, whereas Korean Americans show more "restraint," growing up in the States. I could only conclude that my parents believe Korean Americans show more "restraint" than present Koreans because Korean Americans were raised by parents who obstinately held onto their views about Korean culture fixed from the time period when they left Korea over thirty years ago!

26. Mohanty specifically writes on this. See Mohanty 1997.

27. Theodor Adorno argued for eliminating the concept of authenticity even in the phenomenological/existential tradition. See Adorno 1964. 


\section{REFERENCES}

Adorno, Theodor. 1964. The jargon of authenticity. Trans. Knut Tarnowski and Frederic Will. New York: Routledge.

Alcoff, Linda Martín. 1991-92. The problem of speaking for others. Cultural Critique 20: $5-32$.

. 1998. Real knowing: A response to my critics. Social Epistemology 12 (3): 289_ 305.

- 2000a. Merleau-Ponty and feminist theory on experience. In Chiasms: MerleauPonty's notion of flesh, ed. Fred Evans and Leonard Lawlor. Albany: State University of New York Press.

- 2000b. Who's afraid of identity politics? In Reclaiming identity: realist theory and the predicament of postmodernism, ed. Paula Moya and Michael Hames-Garcia. Los Angeles: University of California Press.

- 2006. Visible identities: race, gender, and the self. New York: Oxford University Press.

Bonjour, Laurence. 1985. The structure of empirical knowledge. Cambridge, Mass.: Harvard University Press.

Dancy, Jonathan. 1985. Introduction to contemporary epistemology. Cambridge, Mass.: Blackwell Publishers, Inc.

Dingwaney, Anuradha, and Lawrence Needham. 1996. The difference that difference makes. Socialist Review 26 (3\&4): 5-48.

Fanon, Frantz. 1967. Black skin, white masks. Trans. Charles Lam Markmann. New York: Grove Press.

Grosz, Elizabeth. 1985. Criticism, feminism and the institution. An interview with Gayatri Chakravorty Spivak. Thesis Eleven 10/11: 175-89.

Harding, Sandra. 1991. Whose science? whose knowledge?: thinking from women's lives. Ithaca, N.Y.: Cornell University Press.

Mohanty, Chandra. 1984. Under western eyes: Feminist scholarship and colonial discourses. Boundary 212 (3): 333-58.

Mohanty, Satya. 1997. Literary theory and the claims of history: postmodernism, objectivity, multicultural politics. Ithaca, N.Y.: Cornell University Press.

Monahan, Michael. 2005. The conservation of authenticity: Political commitment and racial reality. Philosophia Africana 18 (1): 37-50.

Moya, Paula M.L. 1997. Postmodernism, 'realism,' and the politics of identity: Cherríe Moraga and Chicana feminism. In Feminist genealogies, colonial legacies, democratic futures, ed. Jacqui Alexander and Chandra Talpade Mohanty. New York: Routledge.

Narayan, Uma. 1997. Dislocating cultures: identities, traditions, and third-world feminism. New York: Routledge.

Nelson, Lynn Hankinson. 1990. Who knows: from Quine to a feminist empiricism. Philadelphia: Temple University Press.

Quine, W.V.O. 1953. From a logical point of view. Cambridge, Mass.: Harvard University Press.

Scott, Joan W. 1991. The evidence of experience. Critical Inquiry 17 (4): 773-97. 
Sherman, Edward. 2005. Authenticity and diversity: A comparative reading of Charles Taylor and Martin Heidegger. Dialogue 44 (1): 145-60.

Spivak, Gayatri Chakravorty. 1988. Can the subaltern speak? In Marxism and the interpretation of culture, ed. Cary Nelson and Lawrence Greenberg. Chicago: University of Illinois Press.

. 1989. In a word: Interview. Differences 1 (2): 124-56.

Stone-Mediatore, Shari. 2000. Chandra Mohanty and the re-valuing of "experience." In Decentering the center: philosophy for a multicultural postcolonial and feminist world, ed. Uma Narayan and Sandra Harding. Bloomington: Indiana University Press.

Walzer, Michael. 1995. Preface. In Anti-semite and jew, ed. Jean-Paul Sartre. New York: Schocken Books.

Williams, Patricia J. 1991. The alchemy of race and rights. Cambridge, Mass.: Harvard University Press. 